\title{
Iontophoretic Transdermal Delivery of Glycyrrhizin: Effects of pH, Drug Concentration, Co-ions, Current Intensity, and Chemical Enhancers
}

\author{
Rie Yamamoto, ${ }^{*, a}$, Shinri Takasuga, ${ }^{a}$ Katsuya Kominami, ${ }^{a}$ Chiyo Sutoh,${ }^{a}$ Mine Kinoshita, ${ }^{a}$ \\ Kiyoshi Kanamura, ${ }^{a}$ and Kozo Takayama ${ }^{b}$ \\ ${ }^{a}$ Department of Device Development, TTI ellebeau, Inc.; 4-8-8 Higashi-Shinagawa, Shinagawa-ku, Tokyo 140-0002, \\ Japan: and ${ }^{b}$ Department of Pharmaceutics, Hoshi University; 2-4-41 Ebara, Shinagawa-ku, Tokyo 142-8501, Japan. \\ Received July 11, 2013; accepted September 14, 2013
}

The aim of the present study was to evaluate the feasibility of transdermal delivery of glycyrrhizin, an agent used in the treatment of chronic hepatitis $\mathrm{C}$, by cathodal iontophoresis using Ag/AgCl electrodes in vitro. The effects of donor $\mathrm{pH}(\mathrm{pH} 4-7)$, concentration of $\mathrm{drug}(0.025-0.2 \%(\mathrm{w} / \mathrm{v}))$, concentration of external chloride ions $\left(\mathrm{Cl}^{-}\right)(0-133 \mathrm{~mm})$, current strength $\left(0-0.5 \mathrm{~mA} / \mathrm{cm}^{2}\right)$, and permeation enhancers (urea and Tween 80) on the skin permeability of glycyrrhizin were examined in in vitro skin permeation studies using porcine ear skin as the membrane. The cumulative amount of permeated glycyrrhizin and the steady-state skin permeation flux of glycyrrhizin across porcine skin increased in a pH-dependent manner. The skin permeability of glycyrrhizin was independent of the concentration of drug and competed only with a high external $\mathrm{Cl}^{-}$ concentration. The skin permeation flux of glycyrrhizin increased with the current $\left(R^{2}=0.8955\right)$. The combination of iontophoresis and enhancers provided an additive or synergistic effect, and a skin permeation flux of about $60 \mu \mathrm{g} / \mathrm{h} / \mathrm{cm}^{2}$ was achieved. The plasma concentration of glycyrrhizin in humans, extrapolated from the in vitro steady-state permeation flux across porcine skin, was within the therapeutic level. These results suggest that cathodal iontophoresis can be used as a transdermal drug delivery system for glycyrrhizin using reasonable patch sizes and acceptable levels of current intensity.

Key words glycyrrhizin; cathodal iontophoresis; transdermal drug delivery; pig skin; chronic hepatitis

Glycyrrhizin, one of the main constituents of Glycyrrhiza glabra L., is used clinically for the treatment of chronic hepatitis and allergic disorders. ${ }^{1-6)}$ Glycyrrhizin injection is administered in patients with chronic hepatitis $\mathrm{C}$, and its long-term use is effective in preventing the development of hepatocellular carcinoma. ${ }^{1,5,6)}$ Repeated painful intravenous injections decrease the quality of life (QOL) of chronic hepatitis patients. Injection therapy also poses risk of infections to healthcare workers. Oral administration is used clinically, but the bioavailability of glycyrrhizin is extremely low. ${ }^{7)}$ To address these shortcomings, transdermal delivery is a desirable alternative administration route for glycyrrhizin in patients with chronic hepatitis $\mathrm{C}$; however, there are no reports on the topic of transdermal delivery of glycyrrhizin.

Transdermal drug delivery technologies are divided into passive and active methods. For a drug to be delivered passively via the skin, it must have adequate lipophilicity and a molecular weight $(\mathrm{MW})<500{ }^{8,9)}$ Iontophoresis, an active transdermal drug delivery technology, is defined as the administration of water-soluble ionic/charged therapeutic agents through the skin by the application of a low-level electric current $\left(<0.5 \mathrm{~mA} / \mathrm{cm}^{2}\right) .{ }^{9,10)}$ Glycyrrhizin, whose $\mathrm{MW}$ as a free acid is 822.93 , is a polyprotic organic weak acid with three carboxyl groups in its molecular structure. In Japan, a water-soluble monoammonium salt (Fig. 1; MW, 839.96) is used in injected and oral formulations. ${ }^{11,12}$ The three reported dissociation constants of the free acid assayed by the titration method are $3.98\left(\mathrm{p} K_{\mathrm{a} 1}\right), 4.62\left(\mathrm{p} K_{\mathrm{a} 2}\right)$, and $5.17\left(\mathrm{p} K_{\mathrm{a} 3}\right) .{ }^{13)}$ Thus, under physiological conditions, glycyrrhizin exists principally as an anion. Considering the physical properties of glycyrrhi-

The authors declare no conflict of interest.

${ }^{\dagger}$ Present address: Research Center for Pharmaceutical Education, Hoshi University; 2-4-41 Ebara, Shinagawa-ku, Tokyo 142-8501, Japan.

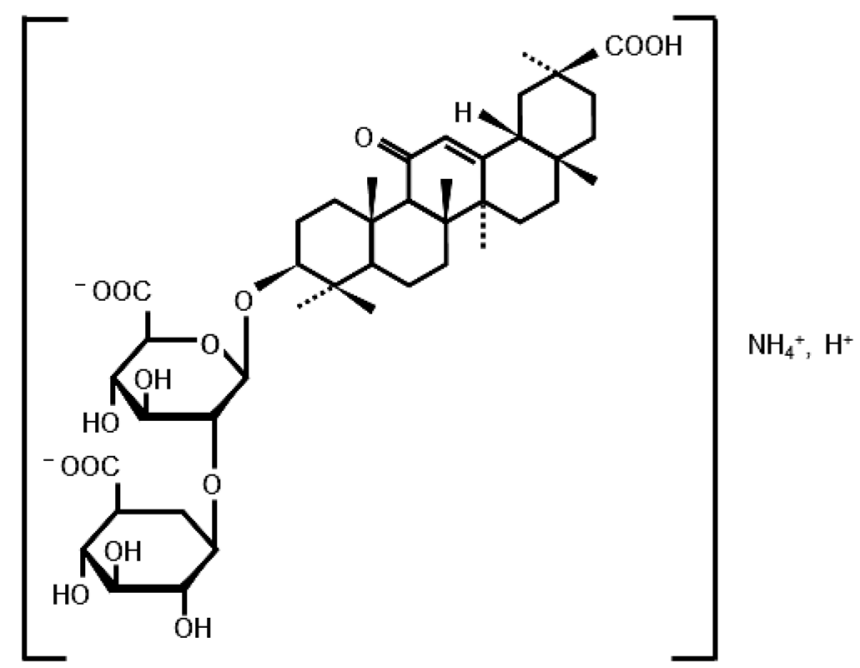

Fig. 1. Chemical Structure of Monoammonium Glycyrrhizinate (MW, 839.96)

zin, cathodal iontophoresis should be applicable to the transdermal delivery of glycyrrhizin. However, to date there have been no reports regarding transdermal iontophoretic delivery of glycyrrhizin.

The aim of the present study was to evaluate the feasibility of transdermal delivery of glycyrrhizin using cathodal iontophoresis in vitro. To examine the effects of $\mathrm{pH}$, concentrations of drug and external chloride ions $\left(\mathrm{Cl}^{-}\right)$, current strength, and permeation enhancers on the skin permeability of glycyrrhizin, in vitro skin permeation studies were performed using porcine ear skin as the membrane. To investigate the feasibility of transdermal glycyrrhizin delivery, the plasma concentration of drug in humans was simulated based on the in vitro steady-state permeation flux of glycyrrhizin across porcine 
skin.

\section{Experimental}

Chemicals and Animals Monoammonium glycyrrhizinate was purchased from Junsei Chemical Co., Ltd. (Tokyo, Japan); 2-[4-(2-hydroxyethyl)-1-piperazinyl] ethanesulfonic acid (HEPES) was purchased from Dojindo Laboratories (Kumamoto, Japan); 0.1 m sodium hydroxide, citric acid monohydrate, sodium chloride, $28 \%$ ammonium, and perchloric acid were obtained from Wako Pure Chemical Industries, Ltd. (Tokyo, Japan). Phosphate-buffered saline (PBS, pH 7.4) was purchased from Invitrogen (New York, U.S.A.). Highperformance liquid chromatography (HPLC) grade methanol was purchased from Merck KGaA (Darmstadt, Germany). Fresh porcine ears were collected from 6- to 7-month-old male pigs from a local abattoir. The experiments were designed according to the guidelines for the Care and Use of Laboratory Animals adopted by the Committee of Animal Care and Use (CACU) at TTI ellebeau Inc., and the protocols were reviewed and approved by the CACU.

Solubility Measurement Monoammonium glycyrrhizinate-saturated solution was prepared using a magnetic stirrer overnight at room temperature $\left(25^{\circ} \mathrm{C}\right)$ and the $\mathrm{pH}$ was adjusted to $3,4,4.5,5,5.5,6$, and 7 using hydrochloric acid or sodium hydrate. Suspensions were centrifuged at $14000 \times \boldsymbol{g}$ for $60 \mathrm{~min}$ and filtered using a Microcon Ultracel YM-3 (Millipore, Billerica, MA, U.S.A.). The supernatants were analyzed by HPLC to measure the concentration of glycyrrhizin as a free acid.

Preparation of Skin Porcine ear skin was prepared for the skin permeation study using previously reported methods. ${ }^{14-16)}$ The ears were cleaned under running cold water, and the hairs were shaved. The whole skin was removed carefully from the outer region of the ear and separated from the underlying cartilage with a scalpel. The skin was then dermatomed with an average thickness of $500 \mu \mathrm{m}$ using a skin graft knife (PM-14701, Padgett Instruments, Inc., Kansas City, MO, U.S.A.). The pieces of skin obtained $(3.5 \mathrm{~cm} \times 3.5 \mathrm{~cm})$ were wrapped individually in plastic film and stored for no more than 1 month at $-80^{\circ} \mathrm{C}$ until use. The required pieces of skin were thawed at room temperature for $30 \mathrm{~min}$ before the skin permeation experiment.

Preparation of Donor Solutions The in vitro skin permeation studies were performed using glycyrrhizin in HEPES solution buffered to $\mathrm{pH} 5,6$, or 7 by addition of $\mathrm{NaOH}$ and adjusted to $\mathrm{pH} 4$ by addition of citric acid. The donor solution was adjusted to $\mathrm{pH} 4,5,6$, or 7 to examine the effect of $\mathrm{pH}$. Other experiments were performed at $\mathrm{pH} 7$.

The drug concentration in the donor solution was 0.025 , $0.05,0.1$, or $0.2 \%(\mathrm{w} / \mathrm{v})$ glycyrrhizin to study the effects of drug concentration, and $0.2 \%(\mathrm{w} / \mathrm{v})$ glycyrrhizin was chosen for other experiments.

To evaluate the effect of external chloride ions, $0.2 \%(\mathrm{w} / \mathrm{v})$ glycyrrhizin in $25 \mathrm{~mm}$ HEPES buffer solution was used with 0 , 13.3, or $133 \mathrm{~mm} \mathrm{NaCl}$.

To assess the combined effects of permeation enhancers and cathodal iontophoresis on the skin permeability of glycyrrhizin, formulations contained appropriate enhancers (either 10\% urea, $20 \%$ urea, $0.75 \%$ Tween $80,1.5 \%$ Tween 80 or combination of $20 \%$ urea and $1.5 \%$ Tween 80$)$ dissolved in $0.2 \%(\mathrm{w} / \mathrm{v})$ glycyrrhizin in $25 \mathrm{~mm}$ HEPES solution.
Skin Permeation Study The in vitro glycyrrhizin skin permeation study by cathodal iontophoresis was performed using side-by-side horizontal diffusion cells (orifice diameter: $10 \mathrm{~mm}$, PermeGear Inc., Hellertown, PA, U.S.A.) with porcine ear skin as the membrane. Porcine skins were mounted between the donor cell and receptor cell, with the stratum corneum facing the donor cell. The donor chamber and the receptor chamber were filled with $3.4 \mathrm{~mL}$ of glycyrrhizin in $25 \mathrm{~mm}$ HEPES and PBS, respectively. The temperature of the solution in the donor and receiver chambers was maintained at $32^{\circ} \mathrm{C}$. $\mathrm{TCT}^{\circledR}$ silver-silver chloride electrodes (Transcu Group Ltd., Singapore) were placed in the sampling ports of the donor and receptor chambers as the cathode and anode, respectively. Both cathodal and anodal electrodes were connected to the electric current controller, and a constant current was applied. Samples $(200 \mu \mathrm{L})$ were collected from the receptor chamber, with replacement of PBS, at 1, 2, 3, 4, 5, and $6 \mathrm{~h}$, and stored at $-20^{\circ} \mathrm{C}$ until analyzed by HPLC.

HPLC Analysis The samples were assayed to measure the concentration of glycyrrhizin as a free acid using reverse phase high-performance liquid chromatography (HPLC) based on previously reported methods. ${ }^{17,18)}$ The HPLC system comprised a CBM-20A system controller, an SIL-20A HT auto-sampler, a DGU-20A3 online degasser, an SPD-20A UV-visible light detector, a CTO-20A3 column oven, and an LC-20AD solvent delivery unit (all from Shimadzu Co., Kyoto, Japan), and was equipped with Capcell Pak C18 MG $(4.6 \mathrm{~mm} \times 150 \mathrm{~mm}$; particle size, $5 \mu \mathrm{m})$ purchased from Shiseido Co., Ltd. (Tokyo, Japan). The solvent used for the mobile phase was methanol- $0.6 \%$ perchloric acid solution adjusted to $\mathrm{pH} 8.0$ with $28 \%$ ammonia solution $(3: 1, \mathrm{v} / \mathrm{v})$; the flow rate was $0.8 \mathrm{~mL} / \mathrm{min}$. The column oven was maintained at $40^{\circ} \mathrm{C}$, and the injection volume was $10 \mu \mathrm{L}$. Glycyrrhizin was detected at $254 \mathrm{~nm}$ by UV detection. Standard curves were linear over the range $1-300 \mu \mathrm{g} / \mathrm{mL}\left(R^{2}>0.999\right)$, and the limit of quantification (LOQ) was $1.0 \mu \mathrm{g} / \mathrm{mL}$.

Data Analysis Data are expressed as mean \pm standard deviation (S.D.). The cumulative amount of glycyrrhizin permeated was plotted against time, and the steady-state skin permeation fluxes were calculated from the straight line portion of the curve. ${ }^{19)}$ Linear regression analysis was performed to examine the correlation between the steady-state skin permeation flux and current intensity. The effects of current strength, drug concentration, and chloride ion concentration on the cumulative amount of glycyrrhizin permeated and steady-state skin permeation flux were analyzed using oneway analysis of variance (ANOVA) followed by Bonferroni's method. The effects of $\mathrm{pH}$ and chemical enhancers were also analyzed by Dunnett's $t$-test. All statistical analyses were performed using SPSS Statistics 17.0 (SPSS Inc., Chicago, IL, U.S.A.). A $p<0.05$ was considered significant.

Simulation of the Plasma Concentration Simulation of the plasma concentration of glycyrrhizin during the iontophoretic delivery in patients with chronic hepatitis $\mathrm{C}$ infection was performed using WinNonlin ${ }^{\mathrm{TM}}$ V.5.2.1 (Pharsight Inc., St. Louis, MO, U.S.A.).

\section{Results}

Solubility of Glycyrrhizin The solubility of glycyrrhizin at different $\mathrm{pH}$ values was determined (Table 1). Solubility of the drug increased in a $\mathrm{pH}$-dependent manner. The solubility 
Table 1. Solubility of Glycyrrhizin in Water at Various $\mathrm{pH}$ Values

\begin{tabular}{cc}
\hline \hline $\mathrm{pH}$ & Solubility $(\%(\mathrm{w} / \mathrm{v}))$ \\
\hline 3.0 & $\mathrm{ND}^{a)}$ \\
4.0 & 0.0258 \\
4.5 & 0.359 \\
5.0 & 1.22 \\
5.5 & 10.8 \\
6.0 & 45.3 \\
7.0 & 47.5 \\
\hline
\end{tabular}

a) $\mathrm{ND}=$ less than the LOQ of the HPLC analysis.

Table 2. Effect of Donor $\mathrm{pH}$ on the Cumulative Amount Permeated after $6 \mathrm{~h}$ and Steady-State Permeation Flux of Glycyrrhizin across Porcine Skin with a Constant Current Supply $\left(0.5 \mathrm{~mA} / \mathrm{cm}^{2}\right)$

\begin{tabular}{ccc}
\hline \hline Donor $\mathrm{pH}$ & $\begin{array}{c}\text { Cumulative amount } \\
\text { permeated }(\mu \mathrm{g})\end{array}$ & $\begin{array}{c}\text { Skin permeation flux } \\
\left(\mu \mathrm{g} / \mathrm{h} / \mathrm{cm}^{2}\right)\end{array}$ \\
\hline 4 & $30.5 \pm 5.5$ & $7.6 \pm 0.9$ \\
5 & $36.1 \pm 7.6$ & $8.6 \pm 1.4$ \\
6 & $48.2 \pm 21.7^{a}$ & $11.6 \pm 5.4^{a)}$ \\
7 & $50.5 \pm 7.5^{a)}$ & $11.4 \pm 0.4$ \\
\hline
\end{tabular}

Data represent the mean \pm S.D. $(n=5-7)$. a) $p<0.05$ compared with $\mathrm{pH} 4$.

Table 3. Effect of Drug Concentration in the Donor Solution on the Cumulative Amount Permeated after $6 \mathrm{~h}$ and Steady-State Permeation Flux of Glycyrrhizin across Porcine Skin with a Constant Current Supply $\left(0.5 \mathrm{~mA} / \mathrm{cm}^{2}\right)$

\begin{tabular}{ccc}
\hline \hline $\begin{array}{c}\text { Drug concentration } \\
(\%(\mathrm{w} / \mathrm{v}))\end{array}$ & $\begin{array}{c}\text { Cumulative amount } \\
\text { permeated }(\mu \mathrm{g})\end{array}$ & $\begin{array}{c}\text { Skin permeation flux } \\
\left(\mu \mathrm{g} / \mathrm{h} / \mathrm{cm}^{2}\right)\end{array}$ \\
\hline 0.025 & $46.9 \pm 19.0$ & $11.2 \pm 4.9$ \\
0.05 & $62.4 \pm 31.0$ & $14.8 \pm 6.6$ \\
0.1 & $69.0 \pm 61.8$ & $16.7 \pm 14.3$ \\
0.2 & $62.8 \pm 29.2$ & $15.9 \pm 7.5$ \\
\hline
\end{tabular}

Data represent the mean \pm S.D. $(n=4-5)$.

was less than the LOQ at $\mathrm{pH} 3$, increased between $\mathrm{pH} 5$ and 6 , and was a maximum $(45-48 \%, w / v)$ at $\mathrm{pH} \geq 6$. Reflecting these results, donor solutions containing $0.025 \%$ glycyrrhizin were used for the examination of the effects of $\mathrm{pH}$ on skin permeability in the $\mathrm{pH}$ range of 4 to 7 , and $\mathrm{pH} 7$ donor solutions were used for all experiments except for the $\mathrm{pH}$ study.

In Vitro Skin Permeation Study Table 2 shows the effects of donor $\mathrm{pH}$ on the skin permeability of glycyrrhizin induced with cathodal iontophoresis $\left(0.5 \mathrm{~mA} / \mathrm{cm}^{2}\right)$. The cumulative amount of glycyrrhizin permeated across porcine skin in vitro increased in a $\mathrm{pH}$-dependent manner. The cumulative amount of drug did not differ between $\mathrm{pH} 4$ and 5 but increased significantly at pH6 and $7(p<0.05)$. The steady-state skin permeation flux of glycyrrhizin did not differ between $\mathrm{pH} 4$ and 5 but increased significantly at pH6 $(p<0.05)$ and nearly significantly at $\mathrm{pH}$. Passive diffusion of the drug using $0.025 \%$ glycyrrhizin in HEPES ( $\mathrm{pH} 4$ and 7 ) was investigated; the cumulative amount of the permeated drug after $6 \mathrm{~h}$ was less than the LOQ (data not shown).

The effects of the concentration of glycyrrhizin in the donor solution are shown in Table 3. The skin permeation profiles of glycyrrhizin at concentrations from 0.025 to $0.2 \%$ across the porcine ear skin with a constant current supply $\left(0.5 \mathrm{~mA} / \mathrm{cm}^{2}\right)$ were identical. The cumulative amount permeated and the steady-state skin permeation flux did not change with glycyr-
Table 4. Effect of Concentration of $\mathrm{Cl}^{-}$in the Donor Solution on the Permeation Parameters of Glycyrrhizin across Porcine Skin with a Constant Current Supply $\left(0.5 \mathrm{~mA} / \mathrm{cm}^{2}\right)$

\begin{tabular}{cccc}
\hline \hline $\begin{array}{c}\text { NaCl concentra- } \\
\text { tion }(\mathrm{mm})\end{array}$ & $\begin{array}{c}\text { Drug molar } \\
\left.\text { fraction }^{a}\right)\end{array}$ & $\begin{array}{c}\text { Cumulative amount } \\
\text { permeated }(\mu \mathrm{g})\end{array}$ & $\begin{array}{c}\text { Skin permeation } \\
\text { flux }\left(\mu \mathrm{g} / \mathrm{h} / \mathrm{cm}^{2}\right)\end{array}$ \\
\hline 0 & 1.000 & $61.1 \pm 20.9$ & $15.5 \pm 4.8$ \\
13.3 & 0.155 & $56.1 \pm 10.9$ & $13.9 \pm 1.4$ \\
133 & 0.018 & $9.4 \pm 4.4^{b, c)}$ & $3.0 \pm 0.9^{b, c)}$ \\
\hline
\end{tabular}

Data represent the mean \pm S.D. $(n=4-6) . \quad a)$ Ratio of [glycyrrhizin] to ([glycyrrhizin] $+\left[\mathrm{Cl}^{-}\right]$) in donor cells is shown. b) $p<0.01$ compared with $0 \mathrm{~mm} \mathrm{NaCl}$. c) $p<0.01$ compared with $13.3 \mathrm{~mm} \mathrm{NaCl}$.

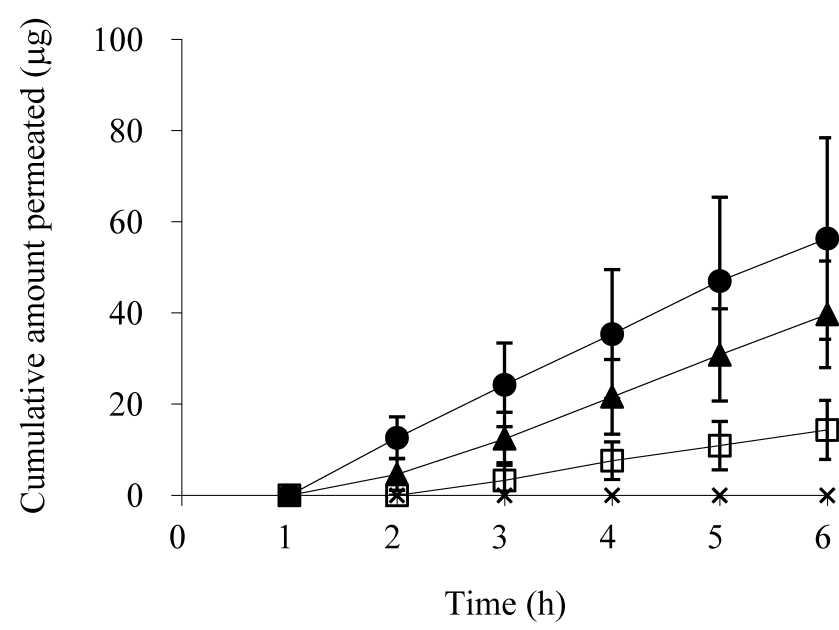

Fig. 2. Effect of Current Strength on Iontophoretic Skin Permeation Profiles of Glycyrrhizin across Porcine Skin

$\times: 0, \square: 0.125, \boldsymbol{\Delta}: 0.25$ and $\bullet: 0.5 \mathrm{~mA} / \mathrm{cm}^{2}$. Each point and bar represent the mean \pm S.D. $(n=3-5)$.

rhizin concentration.

Table 4 shows the effects of the concentration of chloride ions $\left(\mathrm{Cl}^{-}\right)$in donor cells on the skin permeability of glycyrrhizin using the $\mathrm{pH} 7$ donor solution, drug concentration of $0.2 \%$, and current of $0.5 \mathrm{~mA} / \mathrm{cm}^{2}$. The cumulative amount of permeated glycyrrhizin and the steady-state skin permeation flux of glycyrrhizin were significantly lower in $133 \mathrm{mM} \mathrm{Cl}^{-}$compared with in $0 \mathrm{~mm} \mathrm{Cl}^{-}(p<0.01)$ or in $13.3 \mathrm{~mm} \mathrm{Cl}^{-}(p<0.01)$. By contrast, the permeability of glycyrrhizin in $13.3 \mathrm{mM} \mathrm{Cl}^{-}$was nearly equivalent to $0 \mathrm{mM} \mathrm{Cl}^{-}$.

The skin permeability of $0.2 \%$ glycyrrhizin in HEPES ( $\mathrm{pH} 7)$ as the donor solution increased in a current-dependent manner. The cumulative amounts of glycyrrhizin produced by $0.125,0.25$, and $0.5 \mathrm{~mA} / \mathrm{cm}^{2}$ after $6 \mathrm{~h}$ were $14.4,39.7$, and $56.3 \mu \mathrm{g}$, respectively (Fig. 2). The passive diffusion study also included the same formulation as described above; the cumulative amount of glycyrrhizin permeated after $6 \mathrm{~h}$ was less than the LOQ. The steady-state skin permeation flux values for glycyrrhizin across the porcine skin with a constant current supply of $0,0.125,0.25$, and $0.5 \mathrm{~mA} / \mathrm{cm}^{2}$ were 0 (because the cumulative amount of drug was less than the LOQ), 4.31, 11.2 , and $13.9 \mu \mathrm{g} / \mathrm{h} / \mathrm{cm}^{2}$, respectively (Fig. 3). Regression analysis showed a good linear relationship between glycyrrhizin percutaneous flux and current intensity $\left(R^{2}=0.8955\right)$.

Table 5 shows the effects of chemical penetration enhancers in combination with cathodal iontophoresis $\left(0.5 \mathrm{~mA} / \mathrm{cm}^{2}\right)$ on the skin permeability of glycyrrhizin. The steady-state permeation flux was 1.7 times higher with $20 \%$ urea com- 


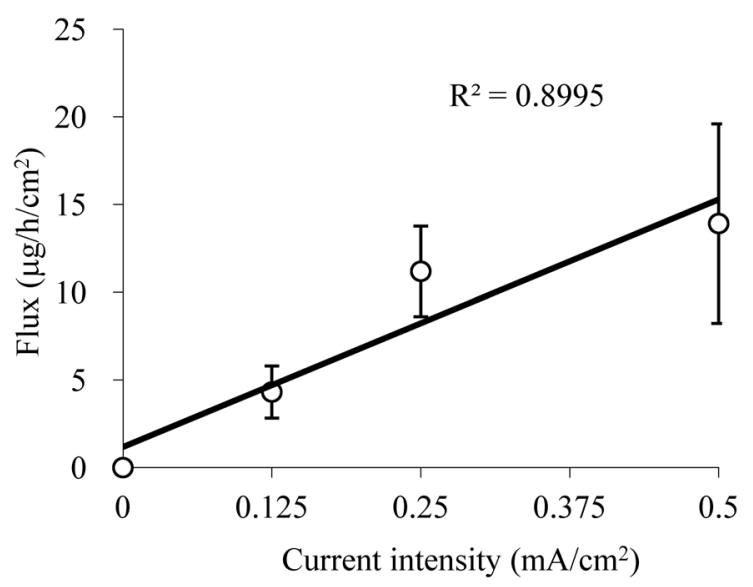

Fig. 3. Relationship between Current Intensity and Steady-State Flux of Glycyrrhizin

Each point and bar represent the mean \pm S.D. $(n=3-5)$.

Table 5. Effect of Enhancers on Iontophoretic Skin Permeation Flux with a Constant Current Supply $\left(0.5 \mathrm{~mA} / \mathrm{cm}^{2}\right)$ and Enhancement Ratio (ER) Relative to the Control

\begin{tabular}{lcc}
\hline \hline \multicolumn{1}{c}{ Donor formulation } & $\begin{array}{c}\text { Skin permeation flux } \\
\left(\mu \mathrm{g} / \mathrm{h} / \mathrm{cm}^{2}\right)\end{array}$ & ER \\
\hline Control (no enhancer) & $23.4 \pm 6.5$ & 1.0 \\
$10 \%$ urea & $26.5 \pm 2.8$ & 1.1 \\
$20 \%$ urea & $39.6 \pm 9.8^{a)}$ & 1.7 \\
$0.75 \%$ Tween 80 & $32.5 \pm 8.7$ & 1.4 \\
$1.5 \%$ Tween 80 & $38.9 \pm 8.4^{a)}$ & 1.7 \\
$20 \%$ urea $+1.5 \%$ Tween 80 & $59.8 \pm 19.0^{b-d)}$ & 2.6
\end{tabular}

Data represent the mean \pm S.D. $(n=4-6) . E R=($ flux with enhancer $) /($ flux with no enhancer). a) $p<0.05$ compared with control. b) $p<0.01$ compared with control. $c$ ) $p<0.05$ compared with $20 \%$ urea. d) $p<0.05$ compared with $1.5 \%$ Tween 80 .

pared with the control (no enhancer) $(p<0.05)$. By contrast, the steady-state permeation flux did not differ significantly between $10 \%$ urea and the control. The flux of glycyrrhizin with $1.5 \%$ Tween 80 was 1.7 times higher $(p<0.05)$ than that of the control, but the flux of glycyrrhizin did not differ between $0.75 \%$ Tween 80 and the control. The permeation flux of the combined formulation, $20 \%$ urea $+1.5 \%$ Tween 80 , was about $60 \mu \mathrm{g} / \mathrm{h} / \mathrm{cm}^{2}$, which was 2.6 times higher than that of the control $(p<0.01)$. The flux of the combined formulation was significantly higher compared with that of $20 \%$ urea or $1.5 \%$ Tween 80 . Passive diffusion studies of $20 \%$ urea, $1.5 \%$ Tween 80 , and the combination were also conducted, but the cumulative amount of glycyrrhizin permeated after $6 \mathrm{~h}$ was less than the LOQ for all conditions (data not shown).

In the any of experiments, there were no obvious differences in the macroscopic observation between sham and current- and/or chemical enhancers-applied skins.

Simulation of the Plasma Concentration The plasma concentration of glycyrrhizin in humans during iontophoretic administration was extrapolated from the in vitro skin permeation flux of glycyrrhizin across porcine skin $\left(60 \mu \mathrm{g} / \mathrm{h} / \mathrm{cm}^{2}\right.$ at $0.5 \mathrm{~mA} / \mathrm{cm}^{2}$ in combination with urea and Tween 80 ). Prior to the simulation, the plasma concentration of glycyrrhizin versus time profile after intravenous injection in patients with chronic hepatitis $\mathrm{C}$ infection as previously reported ${ }^{6)}$ was fitted to a three-compartment model and all pharmacokinetic parameters needed to estimate the plasma concentration of glycyrrhizin were calculated by WinNonlin ${ }^{\mathrm{TM}}$ (V.5.2.1.). As a consequence, the plasma concentration of glycyrrhizin in the steady state in humans during iontophoretic administration was estimated as $1.61-4.84 \mu \mathrm{g} / \mathrm{mL}$ using a $10-30 \mathrm{~cm}^{2}$ patch.

\section{Discussion}

Iontophoresis is a technique used to increase the transdermal delivery of compounds via application of a small electric current. This technique enables the transdermal delivery of hydrophilic charged molecules compared with the conventional passive transdermal approach. ${ }^{19,20)}$ In the present study, the permeation of glycyrrhizin through porcine skin was observed in the range of applied current intensity, from 0.125 to $0.5 \mathrm{~mA} /$ $\mathrm{cm}^{2}$. When no current was applied, the amount of glycyrrhizin permeated was less than the LOQ of the analysis. These data show that the electrical current plays a significant role in the transdermal delivery of glycyrrhizin and suggest that cathodal iontophoresis is a promising transdermal drug delivery system for attaining therapeutic blood levels of glycyrrhizin.

By definition, iontophoresis is the movement of ions under an applied electric field. The optimum $\mathrm{pH}$ for iontophoretic delivery is that at which the compound exists predominantly in an ionized form. ${ }^{21}$ In this study, the solubility of glycyrrhizin at the physiological $\mathrm{pH}$ value was measured before the effect of the donor $\mathrm{pH}$ on glycyrrhizin skin permeability was measured. The solubility of glycyrrhizin was shown to increase in a $\mathrm{pH}$-dependent manner. The three reported dissociation constants of glycyrrhizin assayed by the titration method are $3.98\left(\mathrm{p} K_{\mathrm{a} 1}\right), 4.62\left(\mathrm{p} K_{\mathrm{a} 2}\right)$, and $5.17\left(\mathrm{p} K_{\mathrm{a} 3}\right){ }^{13)}$ When the $\mathrm{pH}$ value of the solution increases from a low to a high value, the stepwise ionization equilibrium of glycyrrhizin increases. Only the fully deprotonated glycyrrhizin exists at $\mathrm{pH}>7$. $^{13}$ ) As a consequence, the solubility of glycyrrhizin increased in a $\mathrm{pH}$-dependent manner. In the $\mathrm{pH}$ range of $4-7$, the cumulative amount of permeated glycyrrhizin and the steady-state skin permeation flux of glycyrrhizin increased in a $\mathrm{pH}$-dependent manner and were greatest at pH6 and 7. These data suggest that the permeation of glycyrrhizin is greatest at $\mathrm{pH} 6$ and 7, at which glycyrrhizin exists mainly in a trianionic form.

Although solubility of glycyrrhizin on $\mathrm{pH} 7$ was 1840 times higher than that of $\mathrm{pH} 4$ (Table 1), skin permeability flux of pH7 was only 1.5 times higher than that of $\mathrm{pH} 4$ (Table 2). This phenomenon may be supported by following discussions: 1) For most small drugs, maximal transport numbers are on the order of $8-15 \%,{ }^{22)}$ by contrast, transport number of iontophoretic glycyrrhizin with $\mathrm{pH} 4,5,6$, and 7 were only $0.15 \%$, $0.17 \%, 0.23 \%$, and $0.22 \%$, respectively. Contribution ratio of ionic form drugs in all molecules was very low, so the skin permeability of glycyrrhizin by cathodal iontophoresis was lightly affected by the $\mathrm{pH}$-dependent changes of solubility. 2) $\mathrm{p} I$ (Isoelectric point) values reported are 4.4 for pig ear skin. ${ }^{22}$ Above this $\mathrm{pH}$, the skin behaves as a permselective membrane and gives rise to the electroosmotic solvent flow. As the $\mathrm{pH}$ is further increased, the skin assumes a negative charge and electroosmotic flow is in the anode-to-cathode direction. ${ }^{23)}$ Based on the above facts, the increasing rate of skin permeability for glycyrrhizin with $\mathrm{pH}$ changing from 4 to 7 was partly canceled out by osmotic flow which direction contrary to the delivery of glycyrrhizin anion by the electric field on the cathodal iontophoresis.

We studied the effects of different drug concentrations in 
the single-ion situation (i.e., with only an endogenous coion such as the chloride ion liberated from the skin and the electrode) in the presence and absence of external $\mathrm{NaCl}$, a common background electrolyte, and the effects of the donor formulation on the iontophoretic transdermal delivery of drug. Previous studies have shown that the transport number of lidocaine increases with drug concentration in the presence of accompanying buffer and that this is independent of the drug concentration in the single-cation situation. ${ }^{22,24)}$ The single-ion situation is advantageous for drug administration because it (a) allows maximal fluxes to be obtained without necessarily using the highest concentration of a drug and (b) introduces a safety mechanism in that the drug flux becomes dependent only on the relative mobilities of the drug and the principal endogenous counterion. ${ }^{22)}$ However, in practice, this ideal situation is difficult to realize because pharmaceutical formulations frequently incorporate charged additives such as buffering agents, viscosity modifiers, and preservatives, which act as external co-ions. Moreover, cathodal iontophoresis using Ag/ $\mathrm{AgCl}$ electrodes liberates $\mathrm{Cl}^{-}$ions from the electrodes, and these ions compete with drug anions for the transport current.

The progressive increase in the $\mathrm{Cl}^{-}$concentration during current application in donor cells decreases the drug anion delivery, as reported for nonsteroidal anti-inflammatory drugs, amino acids, and tripeptides. ${ }^{25-28)}$ In this study, in the singleion situation, the effects of drug concentration on the permeability of glycyrrhizin and the anticipated decrease in the flux with increasing time were not observed. Thus, the iontophoretic delivery of glycyrrhizin would not be affected by endogenous $\mathrm{Cl}^{-}$ions from the electrode or skin surface.

We also investigated the effect of the concentration of external $\mathrm{Cl}^{-}$ions on the skin permeability of the drug using $0.2 \%$ glycyrrhizin in $25 \mathrm{~mm}$ HEPES buffer $(\mathrm{pH} 7)$ as a donor solution with added sodium chloride. The cumulative amount of permeated glycyrrhizin and the steady-state skin permeation flux of glycyrrhizin were significantly lower in $133 \mathrm{~mm}$ $\mathrm{Cl}^{-}$compared with in $0 \mathrm{mM} \mathrm{Cl}^{-}(p<0.01)$ or in $13.3 \mathrm{mM} \mathrm{Cl}^{-}$ $(p<0.01)$. By contrast, the permeability of glycyrrhizin in $13.3 \mathrm{~mm} \mathrm{Cl}^{-}$was nearly equivalent to $0 \mathrm{mM} \mathrm{Cl}^{-}$. The theoretical initial molar fractions of glycyrrhizin anion in the donor cells $\left(\left[\right.\right.$ glycyrrhizin $\left.{ }^{-}\right] /\left(\left[\right.\right.$glycyrrhizin $\left.\left.\left.{ }^{-}\right]+\left[\mathrm{Cl}^{-}\right]\right)\right)$for donor solutions containing $0,13.3$, and $133 \mathrm{mM} \mathrm{Cl}^{-}$were calculated as $1,0.155$, and 0.018 , respectively. The results presented here demonstrate that the skin permeability of glycyrrhizin delivered by cathodal iontophoresis is unaffected by the presence of $\mathrm{Cl}^{-}$as a competing ion if the cathode compartment contains sufficient glycyrrhizin to ensure that the molar fraction is $>15.5 \%$ when used with a donor solution containing $0.2 \%$ glycyrrhizin, an adjusted $\mathrm{pH}$ of 7 , and a constant current supply at $0.5 \mathrm{~mA} / \mathrm{cm}^{2}$ for $6 \mathrm{~h}$. These findings suggest that there is flexibility in the formulation of the donor phase using chloride-containing additives. The exact reasons for this phenomenon are unclear, but the present result is consistent with a previous report showing that the delivery of dexamethasone phosphate from an $\mathrm{Ag} / \mathrm{AgCl}$ cathode is relatively robust to the presence of $\mathrm{Cl}^{-}$in the donor solution. ${ }^{29)}$

Although one of benefits of transdermal iontophoresis is controlled drug delivery based on the percutaneous permeation of a drug in proportion to the current, some molecules have been reported to show no relationship between flux and current density. ${ }^{30)}$ In the present skin permeation study, the in vitro steady-state skin permeation flux of glycyrrhizin increased in a current-dependent manner in the range of 0.125 to $0.5 \mathrm{~mA} / \mathrm{cm}^{2}$. This finding indicates that the percutaneous delivery of glycyrrhizin can be controlled directly by varying the current strength.

The use of chemical penetration enhancers is one of the more widely studied techniques for increasing transdermal drug transport. Many different chemicals can modify the penetration characteristics of different drugs into the skin and can be used in combination with iontophoresis to achieve higher drug penetration. ${ }^{31-35)}$

Hydration of the stratum corneum increases the penetration rate of most (but not all) substances; water opens up the compact structure of the horny layer. ${ }^{34)}$ Urea is a penetration enhancer that promotes horny layer hydration. The addition of urea to an insulin solution together with switching iontophoresis facilitates the absorption of insulin. ${ }^{35)}$ Surfactants are used as emulsifiers, physical stabilizers, and wetting and suspending agents in many topical pharmaceutical formulations. There is a general consensus that nonionic surfactants cause less skin irritation compared with other categories of surfactants; however, they also provide less enhancement of drug permeation. ${ }^{33)}$ Tween 80 , a nonionic surfactant, is thought to disrupt the lipid arrangements in the stratum corneum and to increase the water content of the proteins in the barrier, and thus to increase the flux of diazepam and lorazepam in passive diffusion. ${ }^{36,37)}$

In this study, addition of urea at a concentration of $20 \%$ increased the permeability of glycyrrhizin. Urea may have increased the electrical conductivity of the skin and increased the iontophoretic transdermal delivery of glycyrrhizin through hydration of the stratum corneum. Addition of $1.5 \%$ Tween 80 increased the skin permeability of glycyrrhizin, probably by changing the barrier function and increasing the movement of glycyrrhizin anions through the skin. The iontophoretic flux was greater for the combined enhancer formulation, $20 \%$ urea $+1.5 \%$ Tween 80 , than for the formulations containing only urea or Tween 80 , and reached a maximum of about $60 \mu \mathrm{g} / \mathrm{h} / \mathrm{cm}^{2}$. This increase in glycyrrhizin skin permeation seemed to reflect the synergistic effect of urea and Tween 80, which have different enhancement mechanisms. The passive diffusion values of glycyrrhizin for the formulation with $20 \%$ urea, $1.5 \%$ Tween 80 , and the combination were all less than the LOQ. This indicates that urea and Tween 80 have no enhancing effect on passive diffusion by themselves. Enhancing effect of urea, Tween 80 and the combination seems to require using with iontophoresis. Urea and Tween 80 may be suitable for practical use with iontophoretic transdermal delivery of other drugs.

In previous reports, iontophoresis combined with typical skin permeation enhancers (e.g., terpenes, fatty acids, and esters) has often been performed using the following methods: 1) applying drug solutions containing a high level of alcohol or organic solvent or 2) pretreating the skin with enhancers before the iontophoretic experiments using drug aqueous solutions. ${ }^{38-42)}$ These methods are useful for screening tests or mechanistic analysis of chemical enhancer function in laboratory experiments, but they have little practical value. Urea and Tween 80 , used in the present study, are suitable for practical use because their hydrophilic properties allow them to dissolve easily into aqueous drug donor solutions and because of 
their charge-free behavior, which avoids the risk of competition.

The plasma concentration of glycyrrhizin in humans was extrapolated from the in vitro skin permeation flux of glycyrrhizin across porcine skin $\left(60 \mu \mathrm{g} / \mathrm{h} / \mathrm{cm}^{2}\right.$ at $0.5 \mathrm{~mA} / \mathrm{cm}^{2}$ in combination with urea and Tween 80 ). The estimated plasma concentration of glycyrrhizin in the steady state in humans during iontophoretic administration was $1.61-4.84 \mu \mathrm{g} / \mathrm{mL}$ using a $10-30 \mathrm{~cm}^{2}$ patch. The therapeutic serum level of glycyrrhizin in humans is reported to be $1.7-4.4 \mu \mathrm{g} / \mathrm{mL} .^{11)}$ These findings show that cathodal iontophoresis in combination with urea and Tween 80 can achieve therapeutic blood concentrations of glycyrrhizin with reasonable patch sizes and acceptable current intensity.

Although transdermal iontophoresis offers potential benefits such as controlled drug delivery with less inter- and intra-variations based upon preprogrammed quantity of electric current supplied, avoidance of patient discomfort associated with multiple injection, and high drug delivery rate for macromolecules compared with oral administration and/or passive type of transdermal administration, this technique may cause skin irritation with erythema and/or edema. ${ }^{43}$ We have reported that the long-term application of iontophoresis $(6 \mathrm{~h}$ in guinea pigs and $24 \mathrm{~h}$ in rats) by itself causes only reversible and slight skin erythema. ${ }^{44,45)}$ Chemical enhancers in combination with iontophoresis are known to increase the transdermal permeation rate of macromolecules synergically. ${ }^{10,46)}$ As for skin toxicity in the combination of iontophoresis and the chemical enhancers, there are controversial results have been reported: some enhancers aggravated iontophoresis-induced skin irritation, ${ }^{35}$ and others reduced the skin toxicity. ${ }^{47,48)}$ In the present study there were no obvious differences in macroscopic observations between sham and current in combination with chemical enhancers-applied skins, however, the in vitro skin permeation system is not relevant to evaluate skin irritation. Interestingly, in vivo skin permeation rates for drugs are often higher than those determined in vitro skin permeation studies, indicating the both current intensity and skin toxicity may be reduced in vivo vital condition. ${ }^{44,45,49,50)}$ Taken together, the current intensity, the term of current application, and the composition and concentrations of chemical enhancers for transdermal delivery of glycyrrhizin should be optimized in the further experiments using animals.

\section{Conclusion}

The present study demonstrates that cathodal iontophoresis can control the skin permeation flux of glycyrrhizin in a current-dependent manner and deliver a therapeutic amount of glycyrrhizin at a physiological $\mathrm{pH}$. Thus, transdermal iontophoresis is a potential alternative administration route for glycyrrhizin in the treatment of chronic hepatitis $\mathrm{C}$ to prevent the impairment of the QOL of patients and the risk of infections to healthcare workers that can occur with intravenous administration.

Acknowledgments We thank Mr. M. Ito, Mr. M. Yamauchi, and Mr. Y. Nomoto for their skillful technical support in the in vitro experiments. The basic study of glycyrrhizin began when Cokey Co., Ltd., consigned to us, TTI ellebeau, Inc., a feasibility study of the transdermal drug delivery of glycyrrhizin. We acknowledge Cokey Co., Ltd., for undertak- ing another study using commonly available monoammonium glycyrrhizinate and supporting for the experiments described in this manuscript.

\section{References}

1) van Rossum T. G. J., Vulto A. G., de Man R. A., Brouwer J. T., Schalm S. W., Aliment. Pharmacol. Ther., 12, 199-205 (1998).

2) Yamamura Y., Kawakami J., Santa T., Kotaki H., Uchino K., Sawada Y., Tanaka N., Iga T., J. Pharm. Sci., 81, 1042-1046 (1992).

3) Iino S., Tango T., Matsushima T., Toda G., Miyake K., Hino K., Kumada H., Yasuda K., Kuroki T., Hirayama C., Suzuki H., Hepatol. Res., 19, 31-40 (2001).

4) Miyake K., Tango T., Ota Y., Mitamura K., Yoshiba M., Kato M., Hayashi S., Ikeda Y., Hayashida N., Iwabuchi S., Sato Y., Tomi T., Funaki N., Hashimoto N., Umeda T., Miyazaki J., Tanaka K., Endo Y., Suzuki H., J. Gastroenterol. Hepatol., 17, 1198-1204 (2002).

5) Ikeda K., Hepatol. Res., 37 (Suppl. 2), S287-S293 (2007).

6) van Rossum T. G. J., Vulto A. G., Hop W. C. J., Schalm S. W., Clin. Ther., 21, 2080-2090 (1999).

7) Sasaki K., Yonebayashi S., Yoshida M., Shimizu K., Aotsuka T., Takayama K., Int. J. Pharm., 265, 95-102 (2003).

8) Brown M. B., Martin G. P., Jones S. A., Akomeah F. K., Drug Deliv., 13, 175-187 (2006).

9) Naik A., Kalia Y. N., Guy R. H., Pharm. Sci. Technol. Today, 3, 318-326 (2000).

10) Batheja P., Thakur R., Michniak B., Expert Opin. Drug Deliv., 3, 127-138 (2006).

11) "Interview form of Stronger neo-minophagen $C$ inj.": 〈http://www. eisai.jp/medical/products/di/IF/SMC_A-PA-SY_IF/SMC_A-PA-SY IF.pdf), cited 09 July, 2013.

12) "Interview form of Glycyron tablets.": 〈http://www.eisai.jp/medical/ products/di/IF/GLT_T_IF/GLT_T_IF.pdf), cited 09 July, 2013.

13) Zeng C.-X., Hu Q., Indian J. Chem., 47A, 71-74 (2008).

14) Cázares-Delgadillo J., Ganem-Rondero A., Quintanar-Guerrero D., López-Castellano A. C., Merino V., Kalia Y. N., Eur. J. Pharm. Sci., 39, 387-393 (2010).

15) Patel S. R., Zhong H., Sharma A., Kalia Y. N., Eur. J. Pharm. Biopharm., 66, 296-301 (2007).

16) Sylvestre J. P., Guy R. H., Delgado-Charro M. B., Phys. Ther., 88, 1177-1185 (2008).

17) Koga K., Tomoyama M., Ohyanagi K., Takada K., Biopharm. Drug Dispos., 29, 373-381 (2008).

18) Koga K., Ri S., Ohyanagi K., Takada K., Jpn. J. Pharm. Health Care Sci., 34, 593-600 (2008).

19) Nair V., Pillai O., Poduri R., Panchagnula R., Methods Find. Exp. Clin. Pharmacol., 21, 139-151 (1999).

20) Balaguer-Fernández C., Femenia-Font A., Muedra V., Merino V., López-Castellano A., J. Pharm. Pharmacol., 62, 1096-1102 (2010).

21) Singh P., Liu P., Dinh S. M., "Percutaneous Absorption," ed. by Bronaugh R. L., Maibach H. I., Mercel Dekker, New York, 1999, pp. 633-657.

22) Delgado-Charro M. B., Guy R. H., "Transdermal Drug Delivery," ed. by Guy R. H., Hadgraft J., Mercel Dekker, New York, 2003, pp. 199-225.

23) Kalia N. Y., Naik A., Garrison J., Guy R. H., Adv. Drug Deliv. Rev., 56, 619-658 (2004).

24) Marro D., Kalia Y. N., Delgado-Charro M. B., Guy R. H., Pharm. Res., 18, 1701-1708 (2001).

25) Gay C. L., Green P. G., Guy R. H., Francoeur M. L., J. Control. Release, 22, 57-67 (1992).

26) Hui X., Anigbogu A., Singh P., Xiong G., Poblete N., Liu P., Maibach H. I., J. Pharm. Sci., 90, 1269-1276 (2001).

27) Green P. G., Hinz R. S., Cullander C., Yamane G., Guy R. H., Pharm. Res., 8, 1113-1120 (1991).

28) Green P. G., Hinz R. S., Kim A., Szoka F. C. Jr., Guy R. H., Pharm. Res., 8, 1121-1127 (1991). 
29) Sylvestre J.-P., Diaz-Marin C., Delgado-Charro M. B., Guy R. H., J. Control. Release, 131, 41-46 (2008).

30) Medi B. M., Singh J., Int. J. Pharm., 263, 25-33 (2003).

31) Sinha V. R., Kaur M. P., Drug Dev. Ind. Pharm., 26, 1131-1140 (2000).

32) Wang Y., Thakur R., Fan Q., Michniak B., Eur. J. Pharm. Biopharm., 60, 179-191 (2005).

33) Asbill C. S., El-Kattan A. F., Michniak B., Crit. Rev. Ther. Drug Carrier Syst., 17, 621-658 (2000).

34) Barry B. W., Eur. J. Pharm. Sci., 14, 101-114 (2001).

35) Tomohira Y., Machida Y., Onishi H., Nagai T., Int. J. Pharm., 155, 231-239 (1997)

36) Shokri J., Nokhodchi A., Dashbolaghi A., Hassan-Zadeh D., Ghafourian T., Jalali M. B., Int. J. Pharm., 228, 99-107 (2001).

37) Nokhodchi A., Shokri J., Dashbolaghi A., Hassan-Zadeh D., Ghafourian T., Jalali M. B., Int. J. Pharm., 250, 359-369 (2003).

38) Nair A., Reddy C., Jacob S., Skin Res. Technol., 15, 187-194 (2009).

39) Bounoure F., Skiba M. L., Besnard M., Arnaud P., Mallet E., Skiba M., J. Dermatol. Sci., 52, 170-177 (2008).

40) Bhatia K. S., Singh J., Pharm. Res., 15, 1857-1862 (1998).
41) Rastogi S. K., Singh J., Pharm. Dev. Technol., 1, 97-104 (2005).

42) Femenia-Font A., Balaguer-Fernández C., Merino V., López-Castellano A., Int. J. Pharm., 323, 125-130 (2006).

43) Singh P., Maibach H. I., Crit. Rev. Ther. Drug Carrier Syst., 11, 161-213 (1994).

44) Takasuga S., Yamamoto R., Mafune S., Sutoh C., Kominami K., Yoshida Y., Ito M., Kinoshita M., J. Pharm. Pharmacol., 63, 14371445 (2011)

45) Yamamoto R., Takasuga S., Yoshida Y., Mafune S., Kominami K., Sutoh C., Kato Y., Yamauchi M., Ito M., Kanamura K., Kinoshita M., Int. J. Pharm., 422, 132-138 (2012).

46) Dixit N., Bali V., Baboota S., Ahuja A., Ali J., Curr. Drug Deliv., 4, 1-10 (2007).

47) Kogan A., Garti N., Adv. Colloid Interface Sci., 123-126, 369-385 (2006).

48) Nair V., Panchagnula R., Pharmacol. Res., 47, 555-562 (2003).

49 ) Luzardo-Alvarez A., Delgado-Charro M. B., Blanco-Mendez J., J. Pharm. Sci., 92, 2441-2448 (2003).

50) Chaturvedula A., Joshi D. P., Anderson C., Morris R., Sembrowich W. L., Banga A. K., Pharm. Res., 22, 1313-1319 (2005). 